\title{
Expert's comment concerning Grand Rounds case entitled "Solid variant of aneurysmal bone cyst on the cervical spine of a child: case report, differential diagnosis, and treatment rationale" (by Christos Karampalis, Robert Lenthall, and Bronek Boszczyk)
}

\author{
John P. Dormans • Sean P. Kearney
}

Accepted: 9 January 2013/Published online: 29 January 2013

(C) Springer-Verlag Berlin Heidelberg 2013

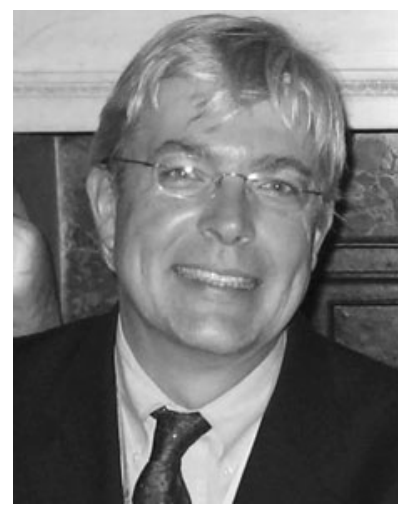

This article reports a case of solid variant aneurysmal bone cyst (S-ABC) in the cervical spine of a child [1]. Aneurysmal bone cyst $(\mathrm{ABC})$ of the vertebral column occurs infrequently and, as the article points out, the solid variant is exceedingly rare in the spine. While MRI can be very helpful in formulating a differential diagnosis and differentiating $\mathrm{S}-\mathrm{ABC}$ from more typical cystic $\mathrm{ABC}$, imaging studies cannot always differentiate $\mathrm{S}-\mathrm{ABC}$ from other benign bone lesions. Performing an incisional biopsy with intra-operative frozen section is an important first step in our approach to treatment of this and other forms of $\mathrm{ABC}$.
Traditional treatment of $\mathrm{ABC}$ with intralesional curettage and bone grafting produced recurrence rates of 10-60\% [2]. To limit recurrence, we recommend a four-step approach to treatment of $\mathrm{ABC}$, including the solid variant form. This includes (1) intralesional curettage, (2) cauterization of the osseous cyst wall, (3) extended curettage with a high-speed diamond burr, and (4) dilute (5\%) phenol application [3]. Titanium instrumentation may be necessary after removal to reestablish spinal stability. As in this case, arterial embolization can be used as an adjunct to surgical excision.

\section{References}

1. Karampalis C, Lenthall R, Boszczyk B (2012) Solid variant of aneurysmal bone cyst on the cervical spine of a child. Case report, differential diagnosis and treatment rationale. Eur Spine $\mathbf{J}$ (submitted)

2. Dormans JP, Moroz L (2007) Infection and tumors of the spine in children. J Bone Joint Surg 89(1):79-97

3. Garg G, Mehta S, Dormans JP (2005) Modern surgical treatment of primary aneurysmal bone cyst of the spine in children and adolescents. J Pediatr Orthop 25:387-392
J. P. Dormans $(\bowtie) \cdot$ S. P. Kearney

Division of Orthopaedic Surgery,

The Children's Hospital of Philadelphia,

3400 Civic Center Boulevard,

Philadelphia, PA 19104, USA

e-mail: dormans@email.chop.edu 